\title{
An Empirical Analysis of Impact of Inclusive Leadership on Employee Engagement in International Non-Government Organizations (INGO's) of Punjab (Pakistan)
}

\author{
Muhammad Shaukat Malik', Farzana Suleman ${ }^{1}$, Naeem Ali ${ }^{2 *}$ and Faiza Arshad ${ }^{3}$ \\ ${ }^{1}$ Institute of Banking and Finance, Bahauddin Zakariya University Multan, Pakistan \\ ${ }^{2}$ National College of Business Administration and Economics, Lahore, Pakistan \\ ${ }^{3}$ The Women University, Multan, Punjab, Pakistan
}

\begin{abstract}
The main objective of this research is to study the relationship between inclusive leadership and employee engagement in International Non-Government Organizations (INGO's) of Punjab (Pakistan). For this, international non-governmental employees were targeted. Using random sampling, 10 INGO out of 42 (including UN Agencies) working in Punjab were selected and a total of 300 international non-governmental employee from selected INGO's were surveyed by questionnaire method involving Likert scale through e-mails and personal visits. With a response rate of $57 \%$, findings are based upon responses from 170 employees.

Findings of the undergoing study put forward that inclusive leadership and engagement of employees are positively associated. The findings add value to the existing literature and provide valuable implications for the managers. This study provides evidence from the nonprofit sector on the important issue of engagement of the employees. Furthermore, the various theories on leadership connect the leadership with employee outcomes, but empirical evidence is still lacking, especially from the perspective of Pakistani context. The above literature gap has been addressed in the study. Some inherent limitations should be kept in mind. Firstly; the only inclusive dimension of leadership is linked with the engagement of the employees. Future studies may address the linkage among other dimensions of leadership and engagement of employees. In addition to this, non-government organizations were targeted for data collection; the findings may vary in other business organizations.
\end{abstract}

Keywords: Employee engagement; Inclusive leadership; INGOs

\section{Introduction}

Individuals and organizations are influenced by the leadership. Leaders affect the both positive outcomes and negative outcomes of the individuals and organizations [1]. Historically, the research on the connection between leadership and employee outcomes focused on the trait approach of leadership and situational leadership theory of leadership [2]. However, organizations are becoming global with the rapid and have diverse cultures due to workforce with various cultural backgrounds [3]. Today, leaders have to manage far more diverse workforce than a decade ago. This trend of diversity is anticipated to go forward in future. The value of attracting and retaining diverse talent is recognized by the global organizations. Diverse talent plays pivotal role in the growth of the business [4].

In this scenario, if the employees lack employee engagement, this source of competitive advantage can be lost or deteriorated. Employees will not enjoy personal well-being and will not exert intellectual effort when they lack Employee engagement [5]. Previous research involves study of the employee engagement from the view of senior management practices, organizational environment, person-job fits, the meaningfulness of job, employee involvement, trust, fairness and line management style most of the times [6-9]. Only a few studies considered the leadership style and even in those studies employee engagement has not been empirically studied considering the role of inclusive style of leadership. This study is to fill this gap and focuses on the empirical study of the connection between Inclusive leadership and engagement of the workforce. Inclusive Leadership can be expected to enhance employee engagement by creating an ethical culture of respect, fairness, cooperation, responsibility, ownership and trust.

Literature has highlighted various antecedents of engagement of employees. Among other, leadership is the key influence of employee engagement. Previous studies focused on the trait approach of leadership, situational leadership theory of leadership while relating leadership with employee outcomes. However, inclusive leadership has been ignored in connecting it with employee outcomes, especially employee engagement, as the inclusive leadership is of key importance in this globalized world where organizations are highly diverse. This study fills the gap by empirical investigation of the relationship between inclusive leadership and employee engagement.

The objectives of this study are to find the role of inclusive leadership in creating engagement of employees. The study has significance from both theoretical and practical perspectives. Findings will contribute to the existing literature and provide valuable recommendations to the managers of the International non-governmental organizations.

\section{Literature Review}

The term of Inclusive leadership refers to the leadership process involving openness, ease of access and availability in the day-to-day interaction of a leader with the followers. It was first used by Nembhard

*Corresponding author: Naeem Ali, National College of Business Administration and Economics, Lahore, Pakistan, Tel: +92 3575-2716; E-mail: naeemali@ncbae.edu.pk

Received May 08, 2017; Accepted June 29, 2017; Published July 03, 2017

Citation: Malik MS, Suleman F, Ali N, Arshad F (2017) An Empirical Analysis of Impact of Inclusive Leadership on Employee Engagement in International NonGovernment Organizations (INGO's) of Punjab (Pakistan). Int J Econ Manag Sci 6 : 441. doi: 10.4172/2162-6359.1000441

Copyright: ( 2017 Malik MS, et al. This is an open-access article distributed under the terms of the Creative Commons Attribution License, which permits unrestricted use, distribution, and reproduction in any medium, provided the original author and source are credited. 
and Edmondson who emphasized on inclusiveness of leadership as a main tool for shaping the positive beliefs of team-members regarding their voice in organizational matters. They argued that an inclusive leader encourages the followers to give their input by remaining available, accessible and open in the organizational matters. The inclusiveness of leadership lies at the heart of relational leadership and it emphasizes on what followers perceive about their leader. Edmondson's has also discussed the aspects of openness, accessibility and openness in his theory. His findings are also consistent with many of the other studies pointing at that particular behavior of leaders such as signaling leader benevolence and perceived support may improve employee's trust in leadership [10]. Further, it has been found that the high-quality of interpersonal relationships among leaders and followers results in enhanced psychological safety in followers [11]. Nembhard and Edmondson focused that when followers perceive that the leaders seeks and encourages their opinions and voice, a sense of psychological safety is aroused in them. Ultimately this sense of psychological safety leads to comfortable expressions of thoughts from the employees [12-15].

Inclusive leader gets best from their employees in order to contribute to the success of the organizations in this turbulent global and national environment. By their skills in adaptability, building associations and evolving talent, inclusive leader upturn the level of innovation and performance of the organization. To attain these benefits, organizations not only need to employ people from diverse backgrounds, but they must incorporate support in its policies and procedures to retain them and get the maximum of their potential by exercising inclusive leadership. It has been already proved that inclusive leadership is one of the key success factors of the strategies of employee diversity and employee engagement. Diverse employees carry their experience and understanding to assist global companies in educating their leadership and implementing a successful strategy of diversity [16,17]. Inclusive Leadership can be defined as "directed towards the doing things with people rather than to people and it stresses respect, recognition, responsiveness and responsibility" and in this study it will be measured in terms of three component factors i.e. support-recognition, communication -action-fairness and selfinterest disrespect. The aim of inclusiveness is to eradicate the social segregation that is that emerges due to diversity in social class, race, ethnicity, gender, religion, and ability [18].

In this age of globalization, inclusion is considered as one of the major challenges faced by the global leaders. Leithwood et al. propose that with ongoing diversity, organizations will need to survive and thrive under uncertain environment, have a larger competence in problem solving at the individual and group level, and inclusively lead a larger workforce from differing backgrounds. Fullan portrays five commonly reinforcing factors essential for successful leadership in the process of change: moral objective, comprehension of change process, knowledge/information creation and sharing, relationship building and coherence making. Sergiovanni also highlights the concern for diversity and proposes that leadership style may play critical role to improve the performance of employees. He puts forward two main factors underlying the failure of leadership: firstly, leadership is most often viewed as a behavior not as an action which results in the major emphasis on dealing the people rather than ideas; secondly, the professional authority is neglected because of undue emphasis on psychological, bureaucratic and technical-rational authority.

Following the similar perception, Lambert et al suggests that leadership must be approached with the constructivist view. This view is described as "the reciprocal processes that enable participants in an educational community to construct common meanings that lead toward a common purpose about schooling". Riehl [18] develops "a comprehensive approach to administration and diversity", focusing specifically on the work of school principals. She concludes that school leaders need to attend to three broad types of task: fostering new meanings about diversity; promoting inclusive practices within schools; and building connections between schools and communities. She goes on to consider how these tasks can be accomplished, exploring how the concept of practice, especially discursive practice, can contribute to a fuller understanding of the work of school principals. This analysis leads the author to offer a more positive view of the potential for school principals to engage in inclusive, transformative developments. She concludes: "When wedded to a relentless commitment to equity, voice, and social justice, administrators' efforts on the tasks of sense making, promoting inclusive cultures and practices in schools, and building positive relationships outside of the school, may indeed foster a new form of practice."Inclusive leadership is part of the social justice leadership family. Power is shared, all individuals' histories, experiences, and knowledge are valued while they work to question and challenge the status quo and its exclusionary and marginalizing practices. Barton states that "central to the demands of an inclusive society are issues of social justice, equity and democratic participation" (p. 233). Ryan claims that social justice can be achieved in a school if all participants are genuinely included in the school.

Riehl agrees with the connection between inclusiveness in school and social justice; she writes that building school cultures that are inclusive support a diverse community. In his examination of how listening and inclusion are related, Veck asks a critical question: how might educators and learners be included within an organization so that they are off and not merely in it? (p. 141). The important words here are "of" and "in." I understand the word "in" to mean little more than occupying space. That is, students and staff members occupy physical space in the school, but the school structure, practices, traditions are set. For my purposes, however, occupying space is not enough. I am more focused on the "of" aspect of inclusion: students and staff members voicing their ideas and issues and also shaping their environment. For many non-dominant group individuals, inclusion in their school will be the first step in their journey for equity. Inclusive leadership involves diverse people united for the common good. Significantly, there is no noticeable difference between the leader and followers in terms of qualifications or social characteristics. Shield posits a framework to help guide educators advocate for social justice. She suggests that "equity of access" to inclusive opportunities is one key component; the student must be able to connect their lived experiences with the curriculum. Social justice leaders must be transformative in the sense that they challenge and change people's understandings of the world and also the practices in schools (p. 128). In this sense, then, educational leaders need to educate the school community members. Inclusive Leadership can be defined as "directed towards the doing things with the people rather than to the people and it stresses respect, recognition, responsiveness and responsibility" and in this study it will be measured in terms of three component factors i.e. support-recognition, communication -actionfairness and self-interest disrespect.

Literature has highlighted various antecedents of engagement of employees. Among other, leadership posits the key influence on employee engagement. Previous studies focused on the trait approach of leadership, situational leadership theory of leadership while relating leadership with employee outcomes. Leadership has influence over the 
attitudes and behaviors of the employees. Leaders influence the ways how employees think. Employee motivation, morale and their level of engagement are highly influenced by the leaders. Leaders affect the followers in multiple ways. According to Jaussi and Dionne, leaders act as role models for their employees. In the same way, Atwater and Carmeli, pointed out that subordinates are energized by the leaders to become more involved in their tasks.

Employees are motivated to complete their tasks and enjoy their jobs. Additionally, leaders provide support to their subordinates and this support by leadership enhances the level of motivation and engagement with the organization. The support from leaders initiates leader - member exchange relations. Employee's level of engagement is upturned when leaders support the actions and decisions of the employees. Similarly, according to Atwater and Carmeli, employees show engaged behavior when the leader is trustworthy and provides consultancy and information to the employees.

In the same way, the theoretical foundation of the impact of leadership on the engagement of the employees is provided by the social exchange theory. Members of the organization present engaged behavior when they are given support and consideration from the leaders. Moreover, plethora of the studies provides the linkage between leadership and employee engagement. Leaders shape the climate of the organization and teams and ultimately, climate of the organization enhance the level of commitment and engagement of the members of organizations [19]. In the same way, Edmondson pointed out that leaders enhance the level of engagement of the employees by showing positive relationships with the peers. They further argued that leaders enhance the engagement psychologically by showing availability, openness and accessibility.

Manager's behavior and organizational culture have a great impact on employee engagement. If employees are engaged, but culture and manager's behavior are not supportive to them at the workplace, engagement will gradually disappear [20]. Leadership is increasingly being viewed from the aspect of inclusion. Leading can produce much better outcomes than just management. For leading a workforce efficiently and getting the true benefit of today, organizations strongly need an inclusive leader. To be an inclusive leader, a leader must develop his awareness about the workforce-differences intelligently and quickly. He must understand at which stage he is and what he needs to do for enhancing his awareness. These stages of awareness involve 1. Defense 2. Minimizing differences 3. Acceptance 4. Adaptation and 5. Integration. Obviously, integration is the ideal stage and the leader on this stage is a true and highly effective inclusive leader. Strong commitment is required for increasing such awareness at personal level. Inclusive leadership is "directed towards doing things with the people rather than to people and it stresses respect, recognition, responsiveness and responsibility". Fairness is one of the core values of a culture created by inclusive leader. Hollander developed a scale to measure inclusive leadership under three principal factor-component of Support - Recognition, Communication-Action-Fairness and Selfinterest - Disrespect.

Leaders influence the attitudes and behaviors of the employees by encouraging them by communicating the significance of the positive behaviors. Burke et al., provides that when leaders involve the employees in the process of decision making and provide consideration the employees then employees feel themselves important. And this sense of being important increases the level of engagement of the employees. In the same way, Nembhard and Edmondson put forward that if leader involves the members and welcome the input provided by the all the members then employees feels safe psychologically and in turn the level of engagement of employees is enhanced. Therefore, it is proposed:

H1: Inclusive leadership has a positive impact on employee engagement (Figure 1)

\section{Research Methodology}

Population for this study is 42 INGO's working in Punjab including 10 United Nations Agencies. Using simple Random sampling, 10 among them Table 1 was studied for Inclusive leadership style and Employee Engagement by getting response from 170 respondents, our response rate was $57 \%$. For this study, all employees of these 10 INGO's have been identified as the respondents considering their diverse backgrounds, managerial levels and professional activeness. Overall 300 questionnaires were distributed, but only 195 were returned. And in these 195, twenty five (25) were discarded due to being incomplete. This study has not involved the responses from the local partners of these INGO's.

Being a previous social worker, I was greatly supported for the
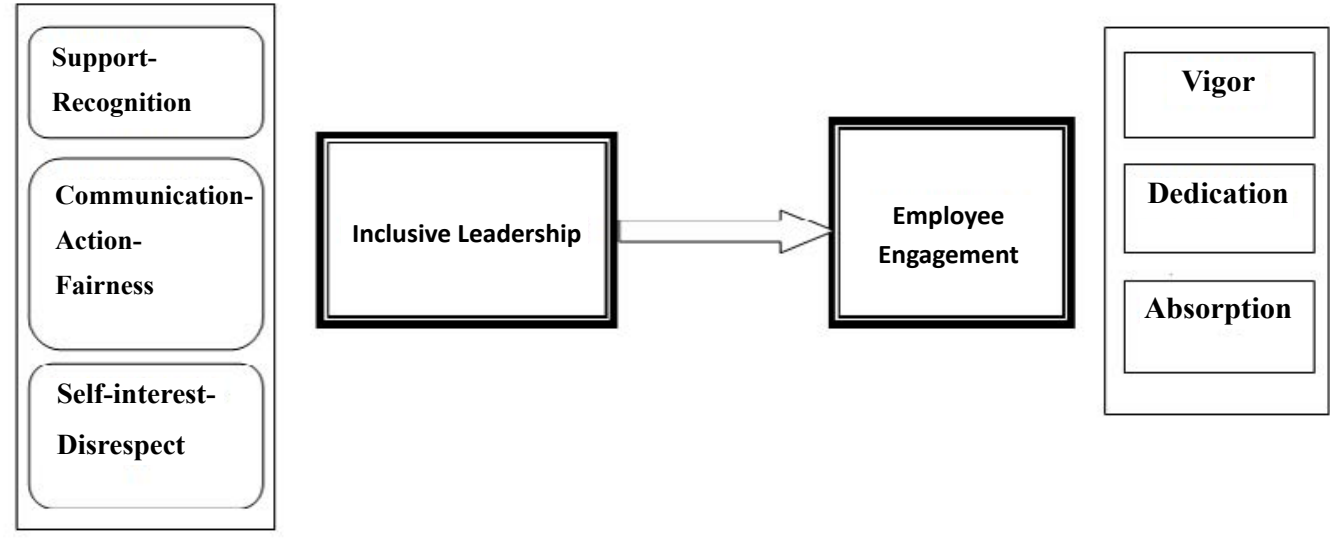

Figure 1: Research Model for this as under. 
survey conducted for this study, by my colleagues who have joined some of these INGO's social interventions, by UNOCHA (United Nations Office for Coordination of Humanitarian Affairs) Lahore, Punjab and social media (like LinkedIn and facebook), in terms of oneto-one meetings and access through e-mails. To obtain the required information and to acquire answers of research questions, total 300 questionnaires were distributed among 10 INGO's working in Punjab. The respondents included lower, middle and senior level employees. In spite of active follow up and use of connections, only 198 questionnaires were received out of which 28 were discarded being incomplete. Therefore 170 questionnaires were selected for analysis, which makes the feedback ratio 57\%. The following Table 1 describes the number of respondents from randomly selected 10 INGO's working in Punjab:

\section{Instrumentation}

Inclusive leadership was measured with the help of sixteen questions/items. The scale was originated by Hollander. The employees were asked to share their perception about the following three behaviors of the employees: i.e. self-interest disrespect, Communication-ActionFairness and Support-Recognition. The responses of the employees about the leadership behavior of the employees were assessed on Likert Scale. Engagement of the employees was assessed by using the instrument of the Schaufeli and Bakker. The scale of engagement of the employees consists of 9 questions. The nine questions assessed the level of absorption, dedication and vigor in the employees. The absorption, dedication and vigor were measured with the three items each.

SPSS was used for data coding and analysis of data to find regression, co-relation and, descriptive statistics.

\section{Data Analysis}

The descriptive analysis was done in order to analyze the demographics of respondents. The descriptive statistics presented below briefly provide the data about age, gender, experience and qualification of the respondents (Table 2).

The factor analysis of sixteen (16) items of inclusive leadership provides one component solution of inclusive leadership, where all the twelve items have factors loading between 0.598 and 0.814 . In addition to

\begin{tabular}{|l|c|}
\hline Name of Organization & No. of Respondents \\
\hline World Vision International & 33 \\
\hline Plan International & 45 \\
\hline Care International & 7 \\
\hline Concern Worldwide & 12 \\
\hline USAID & 26 \\
\hline World Food Programme & 9 \\
\hline UNICEF & 8 \\
\hline Solidarity International & 14 \\
\hline World Health Organization & 9 \\
\hline UNOCHA & 7 \\
\hline Total & 170 \\
\hline
\end{tabular}

Table 1: Respondents Feedback.

\begin{tabular}{|c|c|c|c|c|c|c|c|}
\hline \multicolumn{2}{|c|}{ Gender } & \multicolumn{6}{|c|}{ Age (Years) } \\
\hline Male & Female & \multicolumn{2}{|c|}{$20-30$} & $31-40$ & \multicolumn{2}{|c|}{$41-50$} & Above 50 \\
\hline 117 & 53 & \multicolumn{2}{|l|}{72} & 46 & \multicolumn{2}{|l|}{32} & 20 \\
\hline \multicolumn{4}{|c|}{ Educational Background } & \multicolumn{4}{|c|}{ Experience (Years) } \\
\hline Graduation & Masters & Engineering & Others & 42856 & 43014 & 42309 & Above 15 \\
\hline 19 & 125 & 18 & 8 & 79 & 47 & 34 & 10 \\
\hline
\end{tabular}

this the sample adequacy was observed with KMO and sample is found adequate. Moreover, the variance explained of inclusive leadership is 53.703. Similarly, the factor analysis of nine (9) items of engagement of the employees in the NGOs provides one component solution of engagement of the employees, where all the twelve items have factors loading between 0.783 and 0.927 . In addition to this the sample adequacy was observed with KMO and sample is found adequate. Moreover, the variance explained of engagement of employees is 73.169. The reliability of sixteen (16) items of inclusive leadership was found to be 0.941 . So, the measure of inclusive leadership was come to be reliable. In addition to this, following table also provides the item wise statistics of the sixteen questions of the inclusive leadership. The reliability of nine (09) items of engagement of employees was observed by finding the value of Cronbach's Alpha. The value was found to be 0.953 of nine items of engagement of employees. So, the measure of engagement of employees was come to be reliable. The correlation among inclusive leadership and engagement of employees depicts positive relationships between inclusive leadership and engagement of employees. In addition, all the relationships are significant. In specific, the relationship (correlation) value between inclusive leadership and engagement of employees is 0.498 (Table 3).

The results of regression test put forward that engagement of employees is positively determined by the inclusive leadership. In addition, the impact is significant. In specific, the value of adjused. $R^{2}$ is 0.498 which mean that a 49.8 percent change in the engagement of employees is due to the inclusive leadership. The value of Beta is 0.498 and $t$ is 7.441. Additionally, the fitness of the regression model is confirmed by the F-statistics (Tables 4 and 5).

\section{Discussion}

Findings of the undergoing study put forward that inclusive leadership, engagement of employees and psychological empowerment

\begin{tabular}{|c|c|c|}
\hline & $\begin{array}{c}\text { Inclusive } \\
\text { Leadership }\end{array}$ & $\begin{array}{c}\text { Employee } \\
\text { Engagement }\end{array}$ \\
\hline Inclusive Leadership (N) & 1 & 0.498 \\
\hline Employee Engagement & 0.498 & 1 \\
\hline
\end{tabular}

Table 3: Results of regression.

\begin{tabular}{|c|c|c|c|c|}
\hline & $\mathbf{R}$ & R Sq. & Adj. Sq. $\mathbf{R}$ & Estimated Std. Error \\
\hline 1 & $0.498^{\mathrm{a}}$ & 0.248 & 0.243 & 0.54969 \\
\hline
\end{tabular}

apredictors: (Constant), ICLDR.

\begin{tabular}{|c|c|c|c|c|c|c|}
\hline \multicolumn{7}{|c|}{ Anova $^{\text {b }}$} \\
\hline \multicolumn{2}{|c|}{ Model } & Sum of Squares & Df & Mean Square & F & Sig. \\
\hline 1 & Regression & 16.732 & 1 & 16.732 & 55.374 & $0.000^{\text {a }}$ \\
\hline & Residual & 50.763 & 168 & 0.302 & & \\
\hline & Total & 67.495 & 169 & & & \\
\hline
\end{tabular}

aPredictors: (Constant), Inclusive Leadership

bDependent Variable: Employee Engagement.

Table 4: Model summary.

\begin{tabular}{|c|c|c|c|c|c|c|}
\hline \multicolumn{7}{|c|}{ Coefficients $^{a}$} \\
\hline & \multirow[t]{2}{*}{ Model } & \multicolumn{2}{|c|}{$\begin{array}{l}\text { Unstandardized } \\
\text { Coefficients }\end{array}$} & \multirow{2}{*}{$\begin{array}{c}\text { Standardized } \\
\text { Coefficients } \\
\text { Beta }\end{array}$} & \multirow[t]{2}{*}{$\mathbf{t}$} & \multirow[t]{2}{*}{ Sig. } \\
\hline & & B & Std. Error & & & \\
\hline \multirow[t]{2}{*}{1} & Constant & 1.615 & 0.334 & & 4.832 & 0 \\
\hline & $\begin{array}{l}\text { Inclusive } \\
\text { Leadership }\end{array}$ & 0.587 & 0.079 & 0.498 & 7.441 & 0 \\
\hline
\end{tabular}

aDependent Variable: Employee Engagement.

Table 5: Coefficients. 
are positively associated. In specific, inclusive leadership positively determine the engagement of the employees. This finding is in line with the existing leadership literature on the linkage between leadership and engagement of the employees and confirms the empirical findings of Atwater and Carmeli which entails that LMX (Leader Member Exchange) predicts the level of energy felt by the employees and by building quality relationships at workplace employee can be psychologically engaged; and work of Gebauer, Lowman, and Gordon according to which leaders may play very important role to improve emplyees behaviour at workplace and can reduce the engagement gap. Stating differently, leadership is important tool to upturn the engagement level of employees.

According to Daft and Lane one goal for today's global organizations is to ensure that all people-women, ethnic minorities, younger people, the disabled, older people, racial minorities, as well as white males - are given equal opportunities and treated with fairness and respect. Strong, culturally sensitive leadership can move organizations toward a more inclusive culture, where all individuals are valued and respected for the unique abilities they bring to the workplace. More specifically, inclusive leaders influence the jobs of employees and energize them to do their tasks. The consideration from the inclusive leaders influences the behaviors of employees. Inclusive leaders realize the workers that their role is pivotal in the success of the organizations. By this realization, employees get motivated and shows engaged behavior. In other words, inclusive leadership upturned the level of engagement of the employees which is the key to improve employee and organizational performance. The findings add value to the existing literature and provide valuable implications for the managers. Firstly, previous studies on the leadership and engagement association considered either trait theory or traditional dimensions of leadership such as transactional and transformational leadership. However, in this dynamic business world, inclusive leadership has been emerged. This study is the first attempt to link the inclusive leadership with the engagement of the employees. The findings add value to both the engagement and leadership literature by connecting the inclusive dimension of leadership with the engagement of the employees. Moreover, engagement of the employees was studied generally from the perspective of business organizations. This study provides evidence from the nonprofit sector on the important issue of engagement of the employees. Furthermore, the various theories on leadership connect the leadership with employee outcomes, but empirical evidence is still lacking, especially from the perspective of Pakistani context. Above literature gap has been addressed in the study. Some inherent limitations should be kept in mind during analysis of the results of research highlighted below:

- Firstly, only inclusive dimension of leadership is linked with the engagement of the employees. Future studies may address the linkage among other dimensions of leadership and engagement of employees.

- Secondly International non-government organizations were targeted for data collection, the findings may vary in other business organizations and in even local non-government organizations.

- Thirdly, it was not easily possible to contact employees of targeted INGO's as most of the staff members remain in the field most of the time.

- This research is limited to the province of Punjab and can be more comprehensive if conducted for other provinces too. But due to some constraints like limited resources and shortage of time, it was not feasible to include other provinces too in this research study.

- Employees from all managerial levels were reluctant to share information and respond to questionnaire items because of their organizational policies and security concerns. Also, because they were not concerned with this type of research. It really proved a great hurdle to convince the respondents and HR managers regarding anonymity of the respondents and their organizations.

The future studies may address:

- The linkage among other dimensions of leadership and engagement of employees.

- International non-government organizations were targeted for data collection; the findings may vary in other business organizations and even in local non-government organizations of Punjab.

- The findings relate to INGOs working in Punjab. Findings may vary in other provinces as well.

\section{References}

1. Atwater L, Carmeli A (2009) Leader-member exchange, feelings of energy, and involvement in creative work. The Leadership Quarterly 20: 264-275.

2. Avolio BJ, Bass BM (2001) Developing potential across a full range of Leadership Tm: cases on transactional and transformational leadership: Psychology Press.

3. Daft RL, Lane PG (2005) The leadership experience. Mason, Ohio: Thomson/ South-Western.

4. Dessler G (2013) Human resource management. Boston: Prentice Hall.

5. Bakker AB, Schaufeli WB, Leiter MP, Taris TW (2008) Work engagement: An emerging concept in occupational health psychology. Work \& Stress 22 187-200.

6. Hamel G (2008) The future of management. Human Resource Management International Digest, 16.

7. Hollander E (2012) Inclusive leadership: The essential leader-follower relationship: Routledge.

8. Landorf $\mathrm{H}$, Nevin A (2007) Inclusive global education: implications for social justice. Journal of Educational administration 45: 711-723.

9. Leithwood K, Jantzi D, Steinbach R (1999) Changing leadership for changing times: McGraw-Hill Education (UK)

10. Burke RJ, Koyuncu M, Jing W, Fiksenbaum L (2009) Work engagement among hotel managers in Beijing, China: potential antecedents and consequences. Tourism Review 64: 4-18.

11. Carmeli A, Brueller D, Dutton JE (2009) Learning behaviours in the workplace: The role of high-quality interpersonal relationships and psychological safety. Systems Research and Behavioral Science 26: 81-98.

12. Amabile TM, Schatzel EA, Moneta GB, Kramer SJ (2004) Leader behaviors and the work environment for creativity: Perceived leader support. The Leadership Quarterly 15: 5-32

13. Artiles AJ, Harris-Murri N, Rostenberg D (2006) Inclusion as social justice: Critical notes on discourses, assumptions, and the road ahead. Theory into practice 45: 260-268.

14. Dantley ME, Tillman LC (2006) Social justice and moral transformative leadership. Leadership for social justice: Making revolutions in education $16-30$

15. Nemerowicz G, Rossi E (2014) Education for leadership and social responsibility: Routledge.

16. Nishii LH, Mayer DM (2009) Do inclusive leaders help to reduce turnove in diverse groups? The moderating role of leader-member exchange in the diversity to turnover relationship. Journal of Applied Psychology 94: 1412-1426. 
Citation: Malik MS, Suleman F, Ali N, Arshad F (2017) An Empirical Analysis of Impact of Inclusive Leadership on Employee Engagement in International Non-Government Organizations (INGO's) of Punjab (Pakistan). Int J Econ Manag Sci 6: 441. doi: 10.4172/2162-6359.1000441

Page 6 of 6

17. Vitello SJ, Mithaug DE (2013) Inclusive schooling: National and international perspectives: Routledge.

18. Riehl CJ (2000) The principal's role in creating inclusive schools for diverse students: A review of normative, empirical, and critical literature on the practice of educational administration. Review of educational research 70: 55-81.
19. Mumford MD, Hunter ST (2005) Innovation in organizations: A multi-level perspective on creativity. Research in multi-level issues $4: 11-74$.

20. Perrin T (2005) Reconnecting with employees: Quantifying the value of engaging your workforce. London: Towers Perrin Report. 